\title{
Produtividade e valor nutritivo do capim Tifton 85 irrigado e sobressemeado com aveia
}

Arthur C. Sanches ${ }^{1}$, Eder P. Gomes ${ }^{2}$, Max E. Rickli ${ }^{3}$, Julia P. Fasolin ${ }^{4}$, Mayra R. C. Soares ${ }^{5} \&$ Rafael H. T. B. de Goes ${ }^{6}$

\section{Palavras-chave:}

massa seca

proteína bruta

fibra em detergente neutro

digestibilidade

\begin{abstract}
R E S U M O
O trabalho foi conduzido no período de abril a novembro de 2012, em uma propriedade de produção leiteira, no município de Mariluz, Região Noroeste do Paraná, com o objetivo de avaliar a produtividade, a composição botânica e o valor nutritivo do capim Tifton 85 sobressemeado com aveia, na presença e ausência de irrigação. O delineamento experimental foi de blocos casualizados em parcelas sub-subdivididas, com 4 repetições. As parcelas foram sem e com irrigação. As subparcelas foram constituídas de sobressemeaduras de aveia: FMS 2, IAPAR 61, IPR 126 e um tratamento com o Tifton 85 exclusivo. Os ciclos de coleta compuseram as sub-subparcelas. A irrigação incrementou a produtividade da pastagem com média de $2760,4 \mathrm{~kg} \mathrm{ha}^{-1}$ ciclo $^{-1}$, com a maior relação folha/colmo de 2,8, aumentando a digestibilidade da matéria seca. Os valores de proteína bruta foram maiores no irrigado e na média do irrigado e não irrigado, diminuíram ao longo dos ciclos de coleta de 18,6 para $13,6 \%$. As maiores produtividades foram obtidas por meio das sobressemeaduras das aveias FMS 2 e IPR 126. O Tifton 85 exclusivo apresentou o maior valor de fibra em detergente neutro e o menor valor de digestibilidade.
\end{abstract}

Key words:

dry matter

crude protein

neutral detergent fiber

digestibility

\section{Productivity and nutritive value of Tifton 85 grass irrigated and overseeding with oats}

\begin{abstract}
A B S T R A C T
The study was conducted from April to November, 2012, at a farm of dairy products in the municipality of Mariluz, Nortwest of Parana, with the objective to evaluate the productivity, botanical composition and nutritive value of Tifton 85 overseeding with oats, in the presence and absence of irrigation. The experimental design was a randomized block in split-plot with four replications. The plots were with and without irrigation. The subplots consisted of oats overseeding: FMS 2, IAPAR 61, IAPAR 126 and a treatment with Tifton 85 alone. The collection cycles composed the split plots. Irrigation increased pasture productivity with mean production of $2760.4 \mathrm{~kg} \mathrm{ha}^{-1} \mathrm{cycle}^{-1}$ with higher leaf/stem ratio of 2.8 , increasing dry matter digestibility. The values of crude protein were higher in irrigated and decreased in non-irrigated and irrigated, along the collection cycles from 18.6 to $13.6 \%$. The highest productivities were obtained through overseeding with oats FMS 2 and IPR 126. Tifton 85 alone showed the greatest amount of neutral detergent fiber and lesser digestibility.
\end{abstract}

Protocolo 013.14 - 14/01/2014 • Aprovado em 19/09/2014 • Publicado em 01/02/2015

${ }^{1}$ LEB/ESALQ/USP, Piracicaba, SP. E-mail: arthur_carniato@hotmail.com (Autor correspondente)

${ }^{2}$ FCA/UFGD, Dourados. MS. E-mail: edergomes@ufgd.edu.br

${ }^{3}$ DAG/UEM, Umuarama, PR. E-mail: ricklimax@hotmail.com

${ }^{4}$ DAG/UEM, Umuarama, PR. E-mail: julia_pelegrineli@hotmail.com

${ }^{5}$ DAG/UEM, Umuarama, PR. E-mail: may_shaki@hotmail.com

${ }^{6}$ FCA/UFGD, Dourados, MS. E-mail: rafaelgoes@ufgd.edu.br 


\section{INTRODUÇÃo}

Por se tratar de um país de clima tropical, o potencial produtivo das pastagens no Brasil é elevado, sendo também a forma menos onerosa e mais eficiente na produção pecuária (Dias Filho, 2011), mesmo em regiões onde há queda significativa da produção ocasionada por efeitos climáticos sazonais (Aarons et al., 2013).

Apesar de não ser capaz de eliminar a sazonalidade na região Centro-Sul, a irrigação pode ser utilizada para atenuála obtendo, no período de entressafra (outono/inverno) produtividade da ordem de $50 \%$ da obtida na safra enquanto sem irrigação a produtividade é de 10 a 30\% (Alvim et al., 1986; Rassini, 2004).

Entre as pastagens tropicais o gênero Cynodon tem sido muito utilizado no processo de intensificação da produção de leite. Além de apresentar boa capacidade de produção tem maior resistência à sazonalidade do que outros gêneros, possuindo temperatura basal inferior, da ordem de $12{ }^{\circ} \mathrm{C}$ (Corrêa \& Santos, 2006).

Com relação à produtividade de matéria seca do Tifton 85 , pesquisas apontam para valores de até $55 \mathrm{~kg} \mathrm{ha}^{-1} \mathrm{~d}^{-1}$ (Rocha et al., 2000; Soares Filho et al., 2002) assim como para valores entre 55 a $83 \mathrm{~kg} \mathrm{ha}^{-1} \mathrm{~d}^{-1}$ (Aguiar et al., 2010; Ribeiro \& Pereira, 2011; Fagundes et al., 2012). Com o uso da irrigação as produtividades ultrapassam $96 \mathrm{~kg} \mathrm{ha}^{-1} \mathrm{~d}^{-1}$ (Fonseca et al., 2007; Queiroz et al., 2012; Nogueira et al., 2013; Teixeira et al., 2013) podendo chegar a mais de $165 \mathrm{~kg} \mathrm{ha}^{-1} \mathrm{~d}^{-1}$ (Aguiar et al., 2006).

Além da irrigação a sobressemeadura de aveia vem sendo utilizada como medida prática e econômica que incrementa a produtividade e melhora a distribuição estacional das pastagens no período de entressafra (Furlan et al., 2005; Moreira et al., 2006b); no entanto, a sobressemeadura de aveia em capins do gênero Cynodon nem sempre incrementa, de maneira expressiva, a produtividade de matéria seca da forragem (Moreira et al., 2006a; Rocha et al., 2007). Mesmo assim, a técnica pode ser vantajosa visto que a composição botânica (Olivo et al., 2010; Neres et al., 2011) e o valor nutricional (Castagnara et al., 2012) podem ser melhorados.

Da proporção dos componentes botânicos de folha e colmo resulta a relação folha/colmo que, sendo elevada, aumenta a qualidade da forragem. A sobressemeadura de forrageiras de inverno em capins do gênero Cynodon pode aumentar a relação folha/colmo (Olivo et al., 2010; Neres et al., 2011; Silva et al., 2012).

Pesquisas com sobressemeadura de forrageiras de inverno em cultivares de Cynodon vêm sendo conduzidas com ou sem irrigação. Produtividades de 57 e $76 \mathrm{~kg} \mathrm{ha}^{-1} \mathrm{~d}^{-1}$ de matéria seca total foram obtidas por Rocha et al. (2007) e Olivo et al. (2010), respectivamente, sem irrigação. Com irrigação, Moreira et al. (2006a) e Silva et al. (2012) obtiveram produtividades iguais a 91 e 105,9 kg MS ha-1 $\mathrm{d}^{-1}$, respectivamente, ao contrário de Moreira et al. (2006a) enquanto o segundo autor obteve contribuições significativas de aveia, que chegaram a $50 \%$ do total da forragem produzida.

Em relação ao valor nutritivo, Neres et al. (2011) concluíram que o valor de proteína bruta foi 19,01 e 13,84\% para Tifton 85 sobressemeado com aveia IPR 126 e Tifton 85 exclusivo, respectivamente e constataram que os teores de fibra em detergente neutro e em detergente ácido foram maiores no Tifton 85 exclusivo atingindo valores da ordem de 77 e $38 \%$, enquanto com sobressemeadura de aveia IPR 126 obtiveram 67 e 34\%, respectivamente. Moreira et al. (2006b) verificaram que os resultados de proteína bruta foram de 16,2 e $14,2 \%$ para Tifton 85 consorciado com aveia e milheto e Tifton 85 exclusivo, respectivamente. Em ambos os trabalhos a digestibilidade da matéria seca "in vitro" passou de 60 para $70 \%$ na presença de sobressemeadura.

O objetivo deste trabalho foi avaliar a produtividade, a composição botânica e o valor nutritivo em diferentes ciclos de coleta do capim Tifton 85 exclusivo e sobressemeado com aveia, na ausência e na presença de irrigação.

\section{Material e Métodos}

O experimento foi conduzido em uma propriedade de atividade leiteira no município de Mariluz, PR, no período compreendido entre quatro de maio a seis de novembro de 2012. A propriedade está localizada nas coordenadas geográficas $24^{\circ} 04^{\prime} 19^{\prime \prime}$ de latitude sul, 532 $28^{\prime} 36^{\prime \prime}$ de longitude oeste e $453 \mathrm{~m}$ de altitude. O clima da região, segundo Köppen, é do tipo Cfa (IAPAR, 2012). No período experimental o valor acumulado de precipitação e as médias de umidade relativa, temperatura média e temperatura mínima, foram 503,6 mm, $69,5 \%, 20,5$ e $15,9^{\circ} \mathrm{C}$, respectivamente (Figura 1).

O solo da região é classificado como Latossolo VermelhoEscuro textura Franco-argilo-arenosa (EMBRAPA, 2006); as análises química e granulométrica do solo na camada de $0-0,20$ m estão apresentadas na Tabela 1 .

A área experimental foi composta por oito piquetes de $12 \mathrm{~m}$ de largura e $23 \mathrm{~m}$ de comprimento com área de $276 \mathrm{~m}^{2}$ cada uma constando de quatro piquetes irrigados e quatro não irrigados, com área total de $2208 \mathrm{~m}^{2}$. A área que circundava o experimento era composta de pastagem de Tifton $85 \mathrm{com}$ declividade suave ondulado de $6 \%$. Cada piquete foi dividido em faixas de $3 \mathrm{~m}$ para as sobressemeaduras dos cultivares de aveia, com $69 \mathrm{~m}^{2}$ cada um, totalizando 4 faixas, cada uma com um cultivar diferente utilizando-se das aveias IPR 126, IAPAR 61 e FMS 2 e uma última faixa somente com a pastagem, denominada Tifton 85 exclusivo.

O delineamento experimental adotado foi de blocos casualizados em parcelas sub-subdividas. As parcelas foram irrigadas (I) e não irrigadas (NI) e as subparcelas, sendo uma com Tifton 85 exclusivo e três sobressemeadas com as aveias. As sub-subparcelas foram constituídas pelos ciclos de coleta, variável ao tempo. Foram realizados cinco ciclos de coleta: o primeiro aos 53 dias após a sobressemeadura (53 DASS), o segundo aos 83 dias após a sobressemeadura (83 DASS), o terceiro aos 119 dias após a sobressemeadura (119 DASS), o quarto aos 153 dias após a sobressemeadura (153 DASS) e o quinto aos 186 dias após a sobressemeadura (186 DASS).

A cultura das aveias foi sobressemeada em cobertura sob o Tifton 85 numa taxa de $120 \mathrm{~kg} \mathrm{ha}^{-1}$ em quatro de maio de 2012 . As sementes foram incorporadas através do pisoteio de animais bovinos e a adubação de fundação foi feita em 20 de abril de 2012 com superfosfato simples com aplicação de $180 \mathrm{~kg} \mathrm{ha}^{-1}$ de $\mathrm{P}_{2} \mathrm{O}_{5}$ e calcário dolomítico com PRNT de 70\% aplicandose $1000 \mathrm{~kg} \mathrm{ha}^{-1}$. A irrigação foi composta por aspersores de 


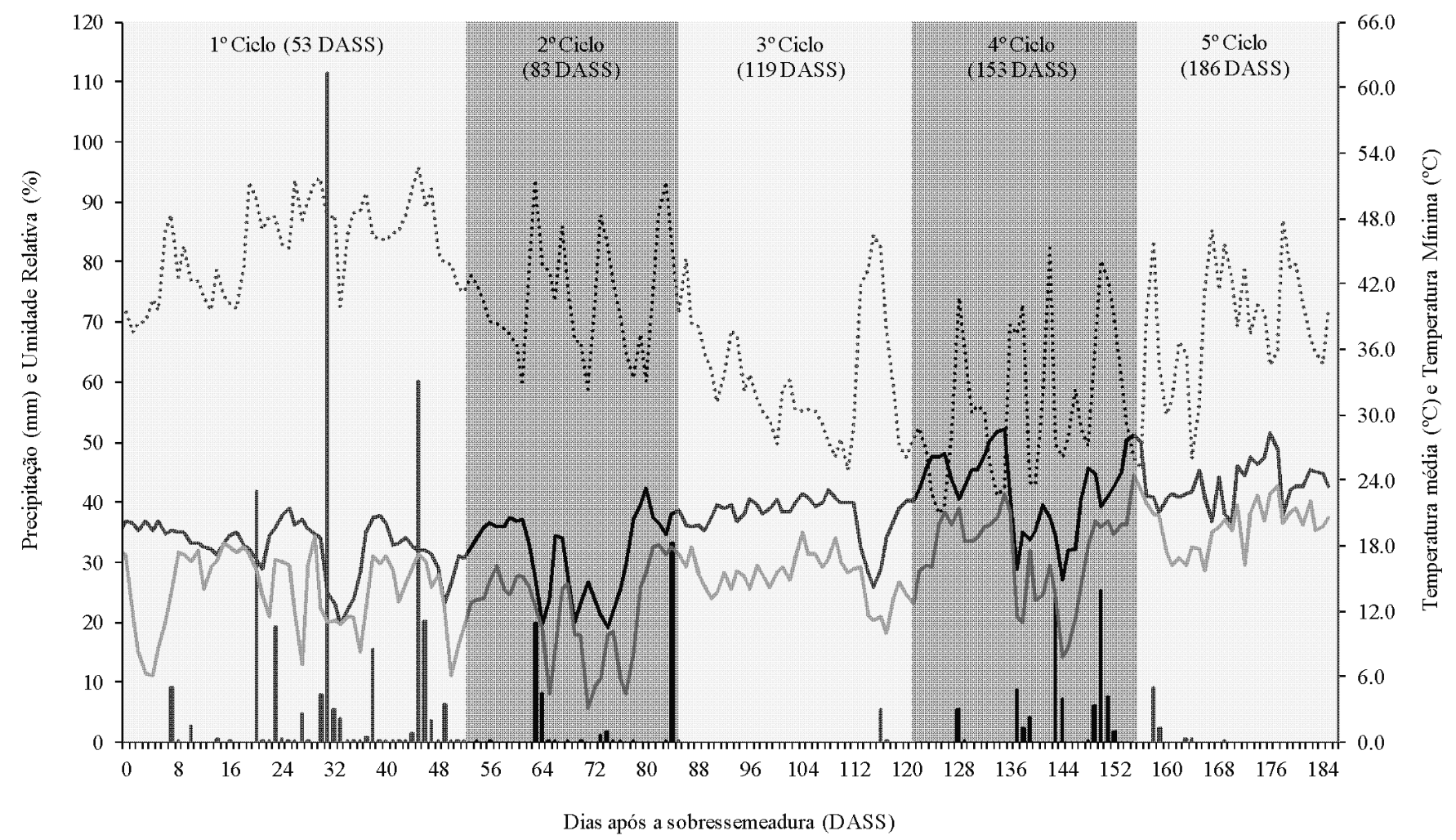

Precipitação $(\mathrm{mm})$

........ Umidade Relativa (\%)

- Temperatura Média $\left({ }^{\circ} \mathrm{C}\right)$

- Temperatura Mínima $\left({ }^{\circ} \mathrm{C}\right)$

Figura 1. Valores de precipitação, temperatura média, temperatura mínima e umidade relativa do ar durante o período experimental de 4 de maio a 6 de novembro de 2012

Tabela 1. Análise química e granulométrica do solo da área experimental em Mariluz, PR, 2012

\begin{tabular}{|c|c|c|c|c|c|c|c|c|c|c|}
\hline $\mathrm{pH}$ & $P$ & $\bar{K}$ & $\mathrm{Ca}$ & $\mathrm{Mg}$ & $\mathrm{H}+\mathrm{Al}$ & $\overline{A l}$ & CTC & Areia & Silte & Argila \\
\hline $\mathrm{CaCl}_{2}$ & $\left(\mathrm{mg} \mathrm{dm}^{-3}\right)$ & \multirow{2}{*}{\multicolumn{6}{|c|}{$\left(\mathrm{cmol}_{\mathrm{c}} \mathrm{dm}^{-3}\right)$}} & & (\%) & \\
\hline 5,6 & 4,65 & & 3,2 & 1,0 & 2,7 & 0,0 & 7,5 & 56,8 & 12,5 & 30,7 \\
\hline
\end{tabular}

baixa vazão no espaçamento de 12 por $12 \mathrm{~m}$, com intensidade de aplicação (IA) 2,4 mm e lâmina de irrigação (LI) total de 150,7 mm (Tabela 2).

O manejo de irrigação foi realizado pelo método da tensiometria, com o monitoramento do potencial de água no solo por meio de tênsiometros instalados a $0,20 \mathrm{~m}$ de profundidade. Foram instalados 12 tensiômetros, sendo seis na área irrigada e seis na área não irrigada. As leituras de tensão foram realizadas três vezes durante a semana, com posterior irrigação sempre que atingia o valor de $10 \mathrm{kPa}$. Segundo Fonseca et al. (2007) o momento adequado a iniciar a irrigação é com 50\% da umidade na capacidade de campo correspondendo a valores maiores de tensão porém, devido à baixa capacidade do reservatório adotaram-se irrigações mais frequentes com o intuito de manter o solo com umidade

Tabela 2. Lâminas de irrigação (LI), eventos de irrigação (EI) e precipitações $(\mathrm{P})$ ocorridas durante o experimento em Mariluz-PR, 2012

\begin{tabular}{ccccc}
\hline $\begin{array}{c}\text { Intervalo } \\
\text { (dias) }\end{array}$ & $\begin{array}{c}\text { Ciclos } \\
\text { de pastejo }\end{array}$ & $\begin{array}{c}\text { LI } \\
\text { (mm) }\end{array}$ & $\begin{array}{c}\text { El } \\
\text { (un.) }\end{array}$ & $\begin{array}{c}\mathbf{P} \\
(\mathbf{m m})\end{array}$ \\
$1-53$ & $1^{0}$ Ciclo (53 DASS) & 10,1 & 4 & 322,4 \\
$54-83$ & $2^{0}$ Ciclo (83 DASS) & 16,4 & 6 & 67,0 \\
$84-119$ & $3^{0}$ Ciclo (119 DASS) & 56,0 & 12 & 6,0 \\
$120-153$ & $4^{0}$ Ciclo (153 DASS) & 47,8 & 12 & 95,2 \\
$154-186$ & $5^{0}$ Ciclo (186 DASS) & 20,4 & 8 & 13,0 \\
& Total & 150,7 & 42 & 503,6 \\
\hline
\end{tabular}

próximo à capacidade de campo. Os valores da tensão de água no solo durante o ciclo experimental estão na Figura 2, com valores médios de tensão ao longo dos ciclos na área irrigada e não irrigada de 5,9 e 7,4 kPa; 7,5 e 10,6 kPa; 12,8 e 27,5 kPa; 11,0 e 29,0 kPa; 7,7 e 13,9 kPa, nos respectivos ciclos.

A lâmina de irrigação (LI) aplicada durante o experimento foi determinada pela diferença entre umidade volumétrica na capacidade de campo $\left(\theta_{c c}\right)$ e a umidade volumétrica atual $(\theta a)$, multiplicadas pela profundidade efetiva da raiz (Z), igual a 400 $\mathrm{mm}$. Foi considerado tensão de água no solo na capacidade de campo $\left(\theta_{c c}\right)$ o valor de $6 \mathrm{kPa}$ conforme Andrade \& Stone (2011). O tempo de irrigação (TI) em cada evento foi obtido pela razão de IA por LI. Os valores de $\theta$ a foram estimados por meio da curva de retenção de água no solo obtida no Laboratório de Relações Água, Solo, Planta e Atmosfera da Universidade Federal da Grande Dourados (UFGD) pelo extrator de Richard's e ajustada pela equação de Genuchten (1980):

$$
\theta \mathrm{a}=0,192+\left[\frac{(0,391-0,192)}{\left[1+\left(0,0003 \sigma_{\mathrm{a}}\right)^{0,324}\right]^{5,6392}}\right] ; \quad\left(\mathrm{R}^{2}=1,00 \text { e } \mathrm{P}<0,01\right)
$$

onde:

$\theta \mathrm{a}$ - umidade volumétrica atual, $\mathrm{cm}^{3} \mathrm{~cm}^{-3}$ 


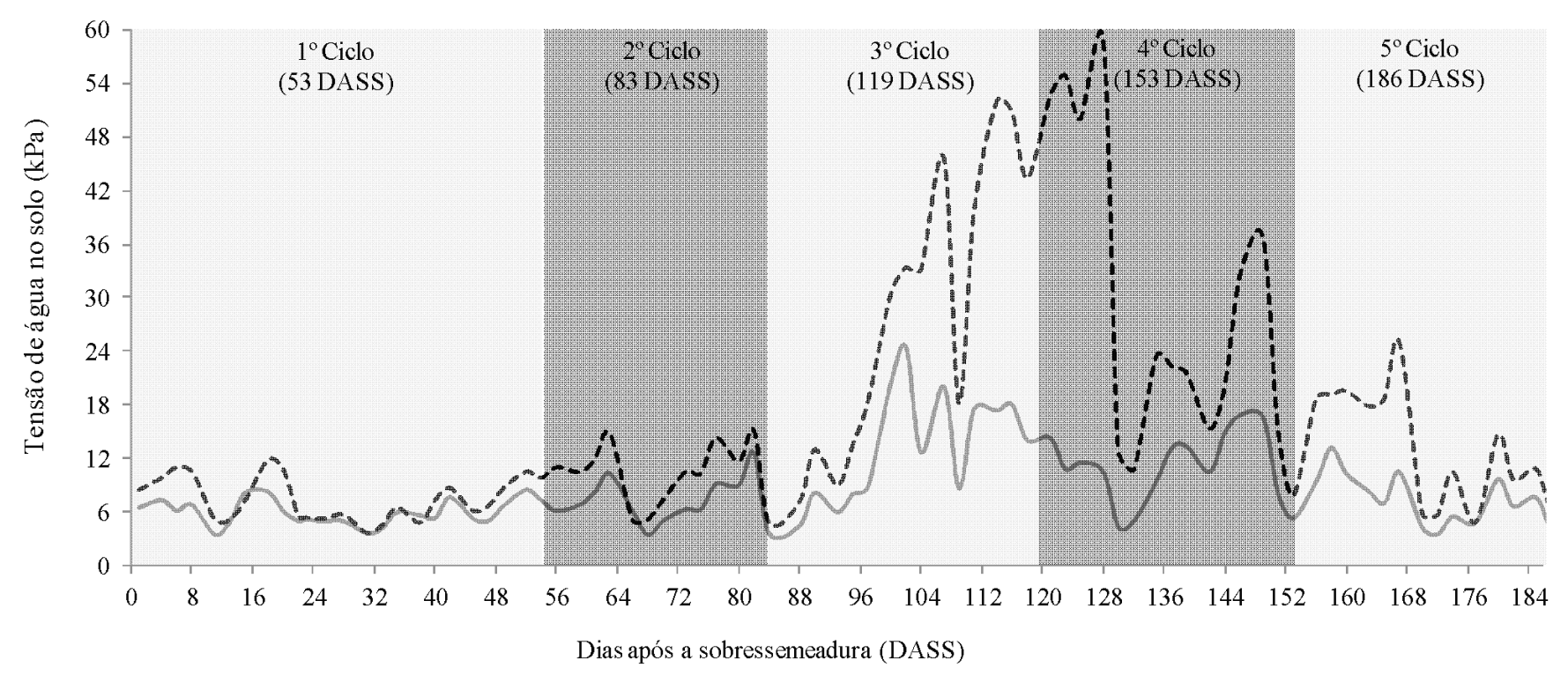

Figura 2. Valores de tensão de água no solo para o Tifton 85 sobressemeado com aveia, com e sem irrigação, em Mariluz-PR, 2012

$$
\sigma_{\mathrm{a}} \quad \text { - tensão atual de água no solo, } \mathrm{kPa}
$$

Os ciclos de coleta foram realizados sempre a partir de uma altura de $0,35 \mathrm{~m}$, sendo lançado ao acaso um quadro de coleta de $0,25 \mathrm{~m}^{2}$ por subparcela. Após a coleta o rebaixamento do pasto foi feito com bovinos de produção leiteira. A forragem (Tifton 85 exclusivo ou Tifton 85 mais aveia) no interior do quadro foi cortada na altura de pastejo, igual a $0,1 \mathrm{~m}$. O procedimento de coleta se repetiu até a extinção da aveia na pastagem. Após cada coleta realizou-se adubação de cobertura com $50 \mathrm{~kg} \mathrm{ha}^{-1}$ de nitrogênio na forma de ureia e $35 \mathrm{~kg} \mathrm{ha}^{-1} \mathrm{de}$ $\mathrm{K}_{2} \mathrm{O}$ na forma de cloreto de potássio.

Em Laboratório a aveia foi separada do capim Tifton 85 e as amostras foram submetidas à separação botânica, subdivididas em folha, colmo e material morto; em seguida, foram encaminhadas à estufa de ar forçado a $65^{\circ} \mathrm{C}$ por $72 \mathrm{~h}$ para determinação da matéria seca (MS); posteriormente, as amostras foram pesadas em balança com precisão de 0,01g; após a pesagem foram estimados os componentes produtivos: produtividade total de forragem (PTF), produtividade de aveia (PA) e produtividade de Tifton 85 (PT85) e a composição botânica: massas de folha (MF), colmo (MC) e material morto (MM); estimou-se, ainda, a relação folha/colmo (RFC).

O valor nutritivo foi analisado sobre a PTF, ou seja, pela composição de aveia mais Tifton 85 nos tratamentos sobressemeados e pelo Tifton 85 exclusivo; com os seguintes componentes bromatológicos: teor de proteína bruta $(\mathrm{PB})$, fibra em detergente neutro (FDN), fibra em detergente ácido (FDA) e digestibilidade "in vitro" da matéria seca (DivMS), conforme Silva \& Queiroz (2002).

Os dados experimentais foram submetidos à análise de variância $(\mathrm{p} \leq 0,05)$ e quando significativas as médias foram comparadas pelo Teste de Tukey $(\mathrm{p} \leq 0,05)$ com a utilização do programa estátistico Assistat 7.6 beta (Silva \& Azevedo, 2009).

\section{Resultados e Discussão}

A produtividade total de forragem (PTF) foi maior com irrigação (Tabela 3) em função da produtividade de Tifton 85 (PT85) com influência da irrigação uma vez que a produtividade de aveia $(\mathrm{PA})$ não foi alterada pela irrigação, com uma contribuição de 505,4 $\mathrm{kg} \mathrm{MS} \mathrm{ha}^{-1}$ ciclo $^{-1}$, sendo superior a PA de $200 \mathrm{~kg} \mathrm{MS} \mathrm{ha}^{-1}$ ciclo-1 $^{-1}$ obtidos por Furlan et al. (2005) e Moreira et al. (2006a), ambos em capim Tifton 85.

Transformando a PTF em taxas de acúmulo de forragem, obtiveram-se 74,2 e 40,6 kg MS ha $\mathrm{kd}^{-1}$ com e sem irrigação, respectivamente. Os dados são coerentes com o maior acúmulo de forragem em pastagens irrigadas, que podem ultrapassar 96 $\mathrm{kg} \mathrm{ha}^{-1}$ (Fonseca et al., 2007; Nogueira et al., 2013; Teixeira et al., 2013) porém há uma amplitude de resultados em condição de sobressemeadura. Sem irrigação, em trabalhos de Cynodon com aveia as taxas de acúmulo variam 20 a $66 \mathrm{~kg} \mathrm{MS} \mathrm{ha}^{-1} \mathrm{~d}^{-1}$ (Rocha et al., 2007; Olivo et al., 2010; Neres et al., 2011; Castagnara et al., 2012); com irrigação, Moreira et al. (2006a) e Furlan et al. (2005) alcançaram, em sobressemeaduras com aveia em Tifton 85, valores de 105,9 e $39 \mathrm{~kg} \mathrm{MS} \mathrm{ha}^{-1} \mathrm{~d}^{-1}$, respectivamente; contudo, o primeiro autor com sobressemeadura tardia (inverno/primavera).

No primeiro ciclo de pastejo, com precipitação de 322,4 $\mathrm{mm}$ (Figura 1), a PTF com irrigação foi semelhante à PTF sem irrigação, iguais a 1263,8 e 1311,8 $\mathrm{kg} \mathrm{MS} \mathrm{ha}^{-1}$, respectivamente. Neste ciclo os valores médios de tensão de água no solo ficaram próximos, iguais a 5,6 $\mathrm{kPa}$ irrigado e 7,4 $\mathrm{kPa}$ não irrigado; no segundo ciclo ocorreram as menores temperaturas média $\left(16,9^{\circ} \mathrm{C}\right)$ e mínima $\left(11,7^{\circ} \mathrm{C}\right)$, com precipitação inferior à do primeiro ciclo $(67 \mathrm{~mm})$, com tensões de água no solo de 7,5 e 10,6 kPa, com e sem irrigação, respectivamente (Tabela 3). Nesta condição climática a produtividade de Tifton 85 (PT85) sem irrigação foi inferior a PTF com irrigação com maior PA sem irrigação contribuída pela menor competitividade da PT85 não irrigada enquanto no terceiro ciclo a precipitação 
Tabela 3. Componentes de produtividade total forragem (PTF), do capim Tifton 85 (PT85) e com sobressemeadura de aveia (PA), por ciclo de pastejo, com e sem irrigação

\begin{tabular}{|c|c|c|c|c|c|c|}
\hline & $\begin{array}{c}1^{0} \text { Ciclo } \\
\text { (53 DASS) }\end{array}$ & $\begin{array}{c}2^{0} \text { Ciclo } \\
\text { (83 DASS) }\end{array}$ & $\begin{array}{c}3^{0} \text { Ciclo } \\
\text { (119 DASS) }\end{array}$ & $\begin{array}{c}4^{0} \text { Ciclo } \\
\text { (153 DASS) }\end{array}$ & $\begin{array}{c}5^{0} \text { Ciclo } \\
\text { (186 DASS) }\end{array}$ & Média \\
\hline & \multicolumn{6}{|c|}{ PTF (kg MS ha-1) } \\
\hline I & $1263,8 \mathrm{aB}$ & $1537,8 \mathrm{aB}$ & 3449,3 aA & $3530,8 \mathrm{aA}$ & $4020,3 \mathrm{aA}$ & $2760,4 a$ \\
\hline $\mathrm{NI}$ & $1311,8 \mathrm{aB}$ & $873,0 \mathrm{bB}$ & $0,0 \mathrm{bC}$ & $2560,5 \mathrm{bA}$ & $2815,0 \mathrm{bA}$ & $1512,1 \mathrm{~b}$ \\
\hline \multirow[t]{2}{*}{ Média } & $1287,8 \mathrm{~B}$ & 1205,4 B & 1724,63 B & $3045,6 \mathrm{~A}$ & $3417,7 \mathrm{~A}$ & 2136,3 \\
\hline & \multicolumn{6}{|c|}{ PA (kg MS ha-1) } \\
\hline I & 398,3 bBC & $547,3 \mathrm{bB}$ & $929,7 \mathrm{aA}$ & 249,3 bC & $316,3 \mathrm{aBC}$ & $493,6 \mathrm{a}$ \\
\hline $\mathrm{NI}$ & $940,0 \mathrm{aA}$ & 885,3 aA & $0,0 \mathrm{bB}$ & $701,3 \mathrm{aA}$ & $58,7 \mathrm{bB}$ & $517,1 \mathrm{a}$ \\
\hline \multirow[t]{2}{*}{ Média } & $669,2 A B$ & $729,8 \mathrm{~A}$ & 464,8 B & 475,3 B & $187,5 \mathrm{C}$ & 505,4 \\
\hline & \multicolumn{6}{|c|}{ PT85 (kg MS ha-1) } \\
\hline I & $965,0 \mathrm{aC}$ & $1107,0 \mathrm{aC}$ & $2752,0 \mathrm{aB}$ & $3343,8 \mathrm{aAB}$ & $3783,1 \mathrm{aA}$ & $2390,2 a$ \\
\hline $\mathrm{NI}$ & $606,8 \mathrm{aC}$ & 209,0 bC & $0,0 \mathrm{bC}$ & 2034,5 bB & 2771,6 bA & $1124,4 \mathrm{~b}$ \\
\hline Média & $785,9 \mathrm{D}$ & $658,0 \mathrm{D}$ & $1376,0 \mathrm{C}$ & $2689,1 \mathrm{~B}$ & $3277,0 \mathrm{~A}$ & 1757,3 \\
\hline
\end{tabular}

I- Irrigado; NI - Não irrigado; DASS - Dias após sobressemeadura Médias seguidas pelas mesmas letras, maiúsculas na linha e minúsculas na coluna, não se diferem pelo teste Tukey ( $\mathrm{p}<0,05)$

foi de $6 \mathrm{~mm}$ com valor de tensão de água no solo para a área irrigada e não irrigada de 12,8 e $27,5 \mathrm{kPa}$, respectivamente; essas condições fizeram com que a forragem não atingisse altura de pastejo na área sem irrigação, em função da baixa umidade no solo e no quarto ciclo a PA volta a ser maior sem irrigação, em consequência do maior período de acúmulo e da menor expressão da PT85 não irrigada; finalmente, o quinto ciclo, com o aumento de temperatura, média de $24,2{ }^{\circ} \mathrm{C}$, é o último com presença de aveia sendo que a irrigação permitiu um período maior de participação visto que a produção é inexpressiva no não irrigado de $58,7 \mathrm{~kg}$ de $\mathrm{MS} \mathrm{ha}^{-1}$.

Não houve incremento de PTF com a sobressemeadura da aveia IAPAR 61 em relação às aveias; nas demais sobressemeaduras a PTF foi superior ao capim Tifton 85 exclusivo (Tabela 4); tal como Silva et al. (2012) verificaram maior produtividade da aveia IPR 126 em relação à IAPAR 61 em sobressemeadura de aveia em capim Estrela-Africana, de valores 51 e $39 \mathrm{~kg} \mathrm{ha}^{-1} \mathrm{MS}^{-1} \mathrm{~d}^{-1}$, respectivamente.

A aveia FMS 2 foi a mais produtiva nos dois primeiros ciclos enquanto a IPR 126 nos dois últimos. A aveia FMS 2 produziu durante quatro ciclos e a produtividade da IAPAR 61 no quinto ciclo foi de apenas $17 \mathrm{~kg} \mathrm{MS} \mathrm{ha}^{-1}$. Os maiores valores de RFC ocorreram nos dois primeiros ciclos de coleta com 2,8 e 3,2 (Tabela 5), respectivamente, provavelmente influenciados pela maior PA nesses ciclos (Tabela 3 ).

A RFC para o Tifton 85 exclusivo foi igual a 1,8 e com sobressemeadura de aveia superior a 2 , atingindo 2,8 na sobressemeadura da aveia FMS 2 obtendo-se, daí, um dossel de

Tabela 5. Composição botânica e relação folha/colmo do capim Tifton 85 ao longo dos ciclos, com e sem sobressemeadura de aveias, com e sem irrigação

\begin{tabular}{|c|c|c|c|c|}
\hline & MF & MC & MF & RFC \\
\hline & & $(\%)$ & & \\
\hline $1^{0}$ ciclo & $60,6 a b$ & 29,0 bc & $10,4 \mathrm{~b}$ & $2,8 \mathrm{a}$ \\
\hline $2^{0}$ ciclo & $64,2 \mathrm{a}$ & $24,8 \mathrm{C}$ & $11,0 \mathrm{~b}$ & $3,2 \mathrm{a}$ \\
\hline $3^{0}$ ciclo* & 53,1 & 33,7 & 13,2 & 1,9 \\
\hline $4^{0}$ ciclo & $50,4 \mathrm{C}$ & $29,8 \mathrm{~b}$ & $19,7 \mathrm{a}$ & $1,7 b$ \\
\hline $5^{0}$ ciclo & $55,3 \mathrm{bc}$ & $38,6 \mathrm{a}$ & $6,2 \mathrm{~b}$ & $1,5 b$ \\
\hline Tifton 85 & $59,1 \mathrm{a}$ & $35,6 \mathrm{a}$ & $5,3 b$ & $1,8 b$ \\
\hline Tifton 85 + FMS 2 & $60,5 \mathrm{a}$ & $28,4 \mathrm{~b}$ & $11,1 \mathrm{a}$ & $2,8 \mathrm{a}$ \\
\hline Tifton 85 + IAPAR 61 & $56,6 \mathrm{a}$ & $28,2 \mathrm{~b}$ & $15,2 \mathrm{a}$ & $2,5 a b$ \\
\hline Tifton 85 + IPR 126 & $54,5 \mathrm{a}$ & $29,9 \mathrm{~b}$ & $15,6 \mathrm{a}$ & $2,1 a b$ \\
\hline I & $64,8 \mathrm{a}$ & $29,3 \mathrm{a}$ & $5,9 \mathrm{~b}$ & $2,8 \mathrm{a}$ \\
\hline $\mathrm{NI}$ & $50,5 b$ & $31,8 \mathrm{a}$ & $17,8 \mathrm{a}$ & $1,8 b$ \\
\hline Média & 57,7 & 30,5 & 11,8 & 2,3 \\
\hline
\end{tabular}

Médias seguidas pela mesma letra não se diferem pelo teste Tukey $(p<0,05)$. *As médias correspondem somente às parcelas irrigadas, pois não houve produção de matéria seca no ciclo não irrigado

Tabela 4. Componentes de produtividade por ciclo de pastejo para pastagens de capim Tifton 85 exclusivo e com sobressemeaduras de aveias

\begin{tabular}{|c|c|c|c|c|c|c|}
\hline \multirow[b]{2}{*}{ Tratamento } & \multicolumn{5}{|c|}{ Produtividade total de forragem (kg MS ha') } & \multirow[b]{2}{*}{ Média } \\
\hline & $\begin{array}{c}1^{0} \text { Ciclo } \\
\text { (53 DASS) }\end{array}$ & $\begin{array}{c}2^{0} \text { Ciclo } \\
\text { (83 DASS) }\end{array}$ & $\begin{array}{c}3^{0} \text { Ciclo } \\
\text { (119 DASS) }\end{array}$ & $\begin{array}{c}4^{0} \text { Ciclo } \\
\text { (153 DASS) }\end{array}$ & $\begin{array}{c}5^{0} \text { Ciclo } \\
\text { (186 DASS) }\end{array}$ & \\
\hline T & $770,5 \mathrm{bBC}$ & $532,5 \mathrm{bC}$ & $1765,0 \mathrm{aB}$ & $3089,0 a b A$ & $3375,0 \mathrm{abA}$ & $1906,4 \mathrm{~b}$ \\
\hline $\mathrm{T}+\mathrm{FMS} 2$ & $1998,0 \mathrm{aB}$ & $1680,5 \mathrm{aB}$ & $1572,5 \mathrm{aB}$ & $3265,0 \mathrm{aA}$ & 3651,7 aA & $2433,5 \mathrm{a}$ \\
\hline$T+161$ & $1118,5 \mathrm{abC}$ & $1188,0 \mathrm{abC}$ & $1530,5 \mathrm{aBC}$ & $2294,5 \mathrm{bAB}$ & $2658,9 \mathrm{bA}$ & $1758,0 \mathrm{~b}$ \\
\hline $\mathrm{T}+\mathrm{I} 126$ & $1264,0 \mathrm{abB}$ & $1420,5 \mathrm{abB}$ & $2030,5 \mathrm{aB}$ & $3534,0 \mathrm{aA}$ & $3985,0 \mathrm{aA}$ & $2446,8 \mathrm{a}$ \\
\hline Média & $1287,75 \mathrm{~B}$ & $1205,37 \mathrm{~B}$ & $1724,6 \mathrm{~B}$ & $3045,6 \mathrm{~A}$ & $3417,6 \mathrm{~A}$ & 2136,2 \\
\hline \multicolumn{7}{|c|}{ Produtividade Total de Tifton $85\left(\mathrm{~kg} \mathrm{MS} \mathrm{ha}^{-1}\right)$} \\
\hline T & $770,5 \mathrm{aA}$ & $532,5 \mathrm{aA}$ & $1765 \mathrm{aA}$ & $3089,0 \mathrm{aA}$ & $3375,0 \mathrm{aA}$ & $1906,4 \mathrm{a}$ \\
\hline $\mathrm{T}+\mathrm{FMS} 2$ & 1079 aA & $555,0 \mathrm{aA}$ & $1097 \mathrm{aA}$ & $2882,0 \mathrm{aA}$ & $3651,7 \mathrm{aA}$ & $1852,9 \mathrm{a}$ \\
\hline$T+161$ & $542,5 \mathrm{aA}$ & $602,0 \mathrm{aA}$ & $1079 \mathrm{aA}$ & $2057,0 \mathrm{aA}$ & $2641,9 \mathrm{aA}$ & $1384,5 b$ \\
\hline $\mathrm{T}+\mathrm{I} 126$ & $751,5 \mathrm{aA}$ & $942,5 \mathrm{aA}$ & $1563 \mathrm{aA}$ & $2728,5 \mathrm{aA}$ & $3439,5 \mathrm{aA}$ & $1885,0 \mathrm{a}$ \\
\hline Média & $785,9 \mathrm{D}$ & $658,0 \mathrm{D}$ & $1376,0 \mathrm{C}$ & $2689,1 \mathrm{~B}$ & $3277,0 \mathrm{~A}$ & 1757,2 \\
\hline \multicolumn{7}{|c|}{ Produtividade total de aveia (kg MS ha') } \\
\hline$T+F M S 2$ & $919,0 \mathrm{aA}$ & $1125,5 \mathrm{aA}$ & $475,5 \mathrm{aB}$ & $383,0 \mathrm{bB}$ & $0,0 \mathrm{bC}$ & $580,6 \mathrm{a}$ \\
\hline$T+\mid 61$ & $576,0 \mathrm{bA}$ & $586,0 \mathrm{bA}$ & $451,5 \mathrm{aA}$ & $237,5 \mathrm{bAB}$ & $17,0 \mathrm{bB}$ & $373,6 \mathrm{~b}$ \\
\hline $\mathrm{T}+\mathrm{I} 126$ & $512,5 \mathrm{bA}$ & $478,0 \mathrm{bA}$ & $467,5 \mathrm{aA}$ & $805,5 \mathrm{aA}$ & $545,5 \mathrm{aA}$ & $561,8 \mathrm{ab}$ \\
\hline Média & $669,2 \mathrm{AB}$ & $729,8 \mathrm{~A}$ & $464,8 \mathrm{~B}$ & $475,3 \mathrm{~B}$ & $187,5 \mathrm{C}$ & 505,4 \\
\hline
\end{tabular}

T - Tifton 85 exclusivo, T + FMS 2 - Tifton 85 com aveia FMS 2, T + I61 - Tifton 85 com aveia lapar 61, T + I 126 - Tifton 85 com aveia IPR 126. DASS - Dias após sobressemeadura. Médias seguidas pelas mesmas letras, maiúsculas na linha e minúsculas na coluna, não se diferem pelo teste Tukey $(p<0,05)$ 
maior qualidade. Trabalho com Coastcros exclusivo e Coastcros com azevém apresentou RFC de 1,4 e 0,9, respectivamente (Olivo et al., 2010). Neres et al. (2011) comprovaram que o Tifton 85 na presença de aveia aumentou sua RFC de 1,3 para 1,4 porém Moreira et al. (2006a) encontraram valores similares de RFC de 0,95 e 0,94 com Tifton mais aveia e milheto e Tifton exclusivo, respectivamente. A maior massa de material morto (MM) no quarto ciclo pode estar relacionada à ausência de coleta nas parcelas não irrigadas no terceiro ciclo acumulando 70 dias e favorecendo a senescência foliar. A média de 11,8\% de MM está próxima do intervalo de 8,2 e 11,6\% encontrados pelos autores Olivo et al. (2010) e Moreira et al. (2006a), respectivamente.

O maior teor de proteína bruta (PB) igual a $18,6 \%$ ocorreu no primeiro ciclo decrescendo até o último atingindo 13,6\% (Tabela 6), que coincide com a tendência de decréscimo de produtividade da aveia e incremento de Tifton 85 nos ciclos (Tabela 4). Trabalhos comprovam a tendência de queda de $\mathrm{PB}$ ao longo dos ciclos em capim de Tifton 85 com aveia, com decréscimos de 17,8 para 11,4\% (Moreira et al., 2012) e 14,8 para $8,0 \%$ (Moreira et al., 2006b) do primeiro ao último ciclo.

A PB média da pastagem sob irrigação foi maior que sem irrigação, colaborada principalmente nos quarto e quinto ciclos, que pode estar relacionada com as tensões de água no solo (Figura 2) iguais a 11 e $29 \mathrm{kPa}$ no quarto ciclo e 7,7 e $13,9 \mathrm{kPa}$ no quinto ciclo, respectivamente que, com maior disponibilidade hídrica, pode ter contribuído para um aporte maior de nutrientes na planta favorecendo alto valor nutricional.

O maior valor de FDN ocorreu no último ciclo de pastejo, igual a 77,3\%, influenciado pela menor quantidade de aveia neste ciclo que, com menor participação da aveia há menor relação folha/colmo, assim maiores quantidades de tecidos fibrosos (Tabela 4). A FDA da pastagem com ou sem irrigação foi semelhante, com média $32,4 \%$, coerente com os valores encontrados em literatura variando de 30 a $40 \%$ para capins do gênero Cynodon com ou sem sobressemeadura de forrageiras de inverno (Moreira et al., 2006b; Neres et al., 2011; Castagnara et al., 2012; Silva et al., 2012); dentre esses, apenas Neres et al. (2011) observaram que o valor da FDA em capim Tifton 85 sobressemeado com aveia diminuiu significativamente de 40 para $36,2 \%$.
A digestibilidade "in vitro" da matéria seca (DivMS) para a irrigação foi superior (Tabela 6). Os maiores valores de DivMS estão compreendidos entre o primeiro e o segundo ciclo, período em que as menores tensões de água no solo (Figura 2) e as maiores produtividades de aveia (Tabela 4) ocorreram justificando um dossel com maior participação de folhas e menor teor de fibras e parede celular (não digeríveis) .

A sobressemeadura de aveia alterou o teor da proteína bruta, tanto nos ciclos como na média geral, sendo que no quinto ciclo não ocorreu resposta devido à queda de produção das aveias (Tabela 7). Para Moreira et al. (2012), o valor de proteína bruta foi semelhante de 14,2 e 14,3\% para Tifton com aveia e Tifton exclusivo, respectivamente; entretanto, outros autores obtiveram aumentos em sobressemeadura, com valores médios de 19 e 17,4\% em aveia mais Tifton e 13 e 13,8\% em Tifton exclusivo (Neres et al., 2011; Castagnara et al., 2012).

A FDN média foi maior no Tifton 85 exclusivo comparado com a sobressemeadura de aveia mas quando comparada por ciclo de coleta, os valores foram semelhantes (Tabela 7), corroborando com os trabalhos que apontam incrementos de 65 a 77\% de FDN do Tifton 85 exclusivo em relação ao sobressemeado (Moreira et al., 2006b; Neres et al., 2011; Castagnara 2012).

A FDA não foi alterada pela sobressemeadura de aveia (Tabela 7) assim como ocorreu em outros trabalhos (Moreira et al.,2006b; Neres et al., 2011; Castagnara et al., 2012; Silva et al., 2012). Autores demonstram que os valores são muito semelhantes de 34,2 e 39,2\% com Tifton 85 sobressemeado e 36,4 e 39,5\% com Tifton 85 exclusivo (Moreira et al., 2006b; Castagnara et al., 2012), respectivamente; assim, a aveia apresenta similaridade de resultados na FDA com relação ao Tifton 85 .

A DivMS (Tabela 7) foi inferior no capim Tifton 85 exclusivo (T85) quando comparado à sobressemeadura de aveia; comportamento semelhante foi observado por Castagnara et al. (2012) com maiores valores de DivMS em Tifton 85 sobressemeado com aveia em relação ao Tifton 85 exclusivo de 83 e $78 \%$, respectivamente, tal como Neres et al. (2011) de 60 e 54\%, respectivamente mas Moreira et al. (2006b) não encontraram diferenças significativas nos valores de DivMS para Tifton 85 exclusivo e sobressemeado, iguais a 56,5 e $54,9 \%$, respectivamente.

Tabela 6. Valor nutritivo do capim Tifton 85 com e sem sobressemeadura de aveias, por ciclo de pastejo, com e sem irrigação

\begin{tabular}{|c|c|c|c|c|c|c|c|}
\hline \multirow{2}{*}{\multicolumn{2}{|c|}{$\begin{array}{c}\text { Componente } \\
\text { bromatológica }\end{array}$}} & \multicolumn{5}{|c|}{ Ciclo de pastejo } & \multirow{2}{*}{ Média } \\
\hline & & $1^{0}$ (53 DASS) & $2^{0}$ (83 DASS) & $3^{0 *}$ (119 DASS) & $4^{0}$ (153 DASS) & $5^{0}$ (186 DASS) & \\
\hline \multirow{3}{*}{ PB } & I & $18,4 \mathrm{aA}$ & $17,5 \mathrm{aAB}$ & 16,9 & $16,3 \mathrm{aBC}$ & $14,7 \mathrm{aC}$ & $16,7 \mathrm{a}$ \\
\hline & $\mathrm{NI}$ & 19,8 aA & $16,0 \mathrm{aB}$ & 0,0 & 13,4 bC & $12,4 \mathrm{bC}$ & $15,2 b$ \\
\hline & Média & $18,6 \mathrm{~A}$ & $16,8 \mathrm{~B}$ & --- & $14,8 \mathrm{C}$ & $13,6 \mathrm{C}$ & 15,7 \\
\hline \multirow{3}{*}{ FDN } & 1 & $71,6 \mathrm{aAB}$ & $68,8 \mathrm{aB}$ & 69,8 & $69,8 \mathrm{bB}$ & $78,1 \mathrm{aA}$ & $72,0 \mathrm{a}$ \\
\hline & $\mathrm{NI}$ & $62,7 \mathrm{bB}$ & $60,7 \mathrm{bB}$ & 0,0 & 80,8 aA & $76,5 \mathrm{aA}$ & $70,2 a$ \\
\hline & Média & $67,1 \mathrm{~B}$ & $64,8 \mathrm{~B}$ & --- & $61,6 \mathrm{~B}$ & $77,3 \mathrm{~A}$ & 71,1 \\
\hline \multirow{3}{*}{ FDA } & I & $33,4 \mathrm{aA}$ & $31,3 \mathrm{aA}$ & 29,9 & $31,2 \mathrm{bA}$ & $34,3 \mathrm{aA}$ & $32,5 \mathrm{a}$ \\
\hline & $\mathrm{NI}$ & $30,1 \mathrm{aBC}$ & $28,2 \mathrm{aC}$ & 0,0 & $37,6 \mathrm{aA}$ & $34,8 \mathrm{aAB}$ & $32,7 \mathrm{a}$ \\
\hline & Média & $31,8 \mathrm{AB}$ & $29,7 \mathrm{~B}$ & --- & $34,4 \mathrm{~A}$ & $34,5 \mathrm{~A}$ & 32,4 \\
\hline \multirow{3}{*}{ DivMS } & I & $81,9 \mathrm{aA}$ & $77,8 \mathrm{bA}$ & 79,6 & $72,9 \mathrm{aB}$ & $79,5 \mathrm{aA}$ & $78,1 \mathrm{a}$ \\
\hline & $\mathrm{NI}$ & $79,4 \mathrm{aA}$ & $81,8 \mathrm{aA}$ & 0,0 & $67,2 \mathrm{bC}$ & $74,9 \mathrm{bB}$ & $75,8 \mathrm{~b}$ \\
\hline & Média & $80,6 \mathrm{~A}$ & $79,7 \mathrm{AB}$ & -- & $70,1 \mathrm{C}$ & $77,3 \mathrm{~B}$ & 76,9 \\
\hline
\end{tabular}

I - Irrigado; NI - Não irrigado; DASS - Dias após sobressemeadura. Médias seguidas pelas mesmas letras, maiúsculas na linha e minúsculas na coluna, não se diferem pelo teste Tukey ( $\mathrm{p}$ $<0,05)$. PB - Proteína bruta; FDN - Fibra em detergente neutro; FDA - Fibra em detergente neutro e DIVMS - Digestibilidade "in vitro" da matéria seca. *As médias correspondem apenas às parcelas irrigadas pois não houve produção de matéria seca no ciclo não irrigado 
Tabela 7. Valor nutritivo por ciclo de pastejo para pastagens de capim Tifton 85 exclusivo e com sobressemeaduras de aveias

\begin{tabular}{|c|c|c|c|c|c|c|c|}
\hline & & \multicolumn{5}{|c|}{ Ciclos de coleta } & \multirow[b]{2}{*}{ Média } \\
\hline & & $1^{0}$ (53 DASS) & $2^{0}$ (83 DASS) & $3^{0}$ (119 DASS) $^{*}$ & $4^{0}$ (153 DASS) & $5^{0}$ (186 DASS) & \\
\hline \multirow{4}{*}{ PB } & $\mathrm{T}$ & $15,0 \mathrm{bA}$ & 12,6 bA & 13,4 & $12,2 \mathrm{cA}$ & $12,3 \mathrm{aA}$ & $13,0 \mathrm{C}$ \\
\hline & $\mathrm{T}+\mathrm{MS}$ & $20,5 \mathrm{aA}$ & $17,5 \mathrm{aB}$ & 19,5 & $13,5 \mathrm{cCb}$ & $13,7 \mathrm{aC}$ & $16,3 b$ \\
\hline & $T+61$ & $19,0 \mathrm{aA}$ & $17,4 \mathrm{aA}$ & 16,7 & $16,2 \mathrm{abAB}$ & $13,8 \mathrm{aB}$ & $16,6 a b$ \\
\hline & $T+126$ & $19,9 \mathrm{aA}$ & $19,5 \mathrm{aA}$ & 17,9 & $17,4 \mathrm{aA}$ & $14,4 \mathrm{aB}$ & $17,8 \mathrm{a}$ \\
\hline \multirow{4}{*}{ FDN } & $\mathrm{T}$ & $72,1 \mathrm{aA}$ & $72,2 \mathrm{aA}$ & 70,6 & $65,2 \mathrm{aA}$ & $76,8 \mathrm{aA}$ & $71,6 \mathrm{a}$ \\
\hline & $T+M S$ & $67,8 \mathrm{aA}$ & $62,1 \mathrm{aA}$ & 66,2 & $60,3 \mathrm{aA}$ & $77,3 \mathrm{aA}$ & $66,9 \mathrm{~b}$ \\
\hline & $T+61$ & $63,5 \mathrm{aA}$ & $59,7 \mathrm{aA}$ & 69,0 & $62,8 \mathrm{aA}$ & $78,3 \mathrm{aA}$ & $66,1 \mathrm{~b}$ \\
\hline & $T+126$ & $65,2 \mathrm{aA}$ & $65,1 \mathrm{aA}$ & 73,4 & $58,0 \mathrm{aA}$ & $76,9 \mathrm{aA}$ & $66,3 b$ \\
\hline \multirow{4}{*}{ FDA } & T & $30,6 \mathrm{aA}$ & $30,9 \mathrm{aA}$ & 29,6 & $32,1 \mathrm{aA}$ & 33,5 aA & $31,8 \mathrm{a}$ \\
\hline & $T+M S$ & $33,2 \mathrm{aA}$ & $30,5 \mathrm{aA}$ & 31,2 & 36,0 aA & 35,8 aA & $33,9 \mathrm{a}$ \\
\hline & $T+61$ & $32,4 \mathrm{aA}$ & $27,1 \mathrm{aA}$ & 29,6 & $34,7 \mathrm{aA}$ & $34,2 \mathrm{aA}$ & $32,1 \mathrm{a}$ \\
\hline & $T+126$ & 30,7 aA & 30,5 aA & 29,4 & 34,9 aA & 34,6 aA & $32,7 \mathrm{a}$ \\
\hline \multirow{4}{*}{ DivMS } & $\mathrm{T}$ & $75,5 \mathrm{bAB}$ & $75,2 \mathrm{bB}$ & 79,0 & $70,9 \mathrm{abB}$ & $81,2 \mathrm{aA}$ & $75,7 \mathrm{~b}$ \\
\hline & $T+M S$ & $82,4 \mathrm{aA}$ & $80,9 \mathrm{aA}$ & 76,2 & $66,4 \mathrm{bB}$ & $77,6 \mathrm{abA}$ & $76,8 \mathrm{a}$ \\
\hline & $T+61$ & 82,3 aA & 81,6 aA & 79,2 & $68,9 \mathrm{abB}$ & 74,6 bB & $76,9 \mathrm{a}$ \\
\hline & $T+126$ & $82,3 \mathrm{aA}$ & $81,3 \mathrm{aA}$ & 84,0 & $74,0 \mathrm{aB}$ & 75,4 bB & $78,3 \mathrm{a}$ \\
\hline
\end{tabular}

Médias seguidas pelas mesmas letras, maiúsculas na linha e minúsculas na coluna, não diferem entre si pelo teste Tukey ( $p<0.05)$; PB - Proteína bruta; FDN - Fibra em detergente neutro; FDA - Fibra em detergente neutro e DivMS - Digestibilidade "in vitro" da matéria seca. *As médias correspondem somente às parcelas irrigadas pois não houve produção de matéria seca no ciclo não irrigado; DASS - Dias após sobressemeadura

\section{Conclusões}

1. A irrigação aumenta a produtividade total de forragem, também promove maior relação folha/colmo, maior digestibilidade in vitro e maior teor de proteína bruta da forragem.

2. As sobressemeaduras com as variedade de aveia FMS 2 e IPR 126 proporcionam maior produtividade total de forragem sendo a FMS 2 mais produtiva nos dois primeiros ciclos e a IPR 126 nos dois últimos ciclos. A aveia FMS 2 produziu, durante quatro ciclos, um ciclo a menos que as aveias IPR 126 e IAPAR 61.

3. O capim Tifton 85 exclusivo apresenta maior teor de fibra em detergente neutro e menor teor de digestibilidade in vitro.

4. O teor de proteína bruta diminui em função dos ciclos de coleta em resposta ao decréscimo de produtividade da aveia e aumento da produtividade do capim Tifton 85 .

\section{Literatura Citada}

Aarons, S. R.; Melland, A. R.; Dorling, L. Dairy farm impacts of fencing riparian land: Pasture production and farm productivity. Journal of Environmental Management, v.130, p.255-266, 2013. http:// dx.doi.org/10.1016/j.jenvman.2013.08.060

Aguiar, A.; Drumond, L.; Felipini, T.; Pontes, P.; Silva, A. Características de crescimento de pastagens irrigadas e não irrigadas em ambiente de cerrado. FAZU em Revista, n.2, p.22-26, 2010.

Aguiar, A. D.; Drumond, L.; Camargo, A.; Minma, J. H.; Scandiuzzi, R.; Resende, J.; Aponte, J. Parâmetros de crescimento de uma pastagem de tifton 85 ("Cynodon dactylon" x "Cynodon nlemfuensis" cv. Tifton 68) irrigada e submetida ao manejo intensivo do pastejo. FAZU em Revista, n.3, p.25-27, 2006.

Alvim, M. J.; Botrel, M. A.; Novelly, P. E. Produção de gramíneas tropicais e temperadas, irrigadas na época da seca. Revista da Sociedade Brasileira de Zootecnia, v.15, p.384-392, 1986.

Andrade, R. S.; Stone, L. F. Estimativa da umidade na capacidade de campo em solos sob Cerrrado. Revista Brasileira de Engenharia Agrícola e Ambiental, v.15, p.111-116, 2011. http://dx.doi. org/10.1590/S1415-43662011000200001
Castagnara, D. D.; Neres, M. A.; Oliveira, P. S. R. D.; Jobim, C. C.; Três, T. T.; Mesquita, E. E.; Zambom, M. A. Use of a conditioning unit at the haymaking of Tifton 85 overseeded with Avena sativa or Lolium multiflorum. Revista Brasileira de Zootecnia, v.41, p.13531359, 2012. http://dx.doi.org/10.1590/S1516-35982012000600006

Corrêa, L. A.; Santos, P. M. Irrigação de pastagens formadas por gramíneas forrageiras tropicais. São Carlos: Embrapa Pecuária Sudeste, 2006. 6p. Comunicado Técnico, 48

Dias Filho, M. B. Os desafios da produção animal em pastagens na fronteira agrícola brasileira. Revista Brasileira de Zootecnia, v.40, p.243-252, 2011.

EMBRAPA - Empresa Brasileira de Pesquisa Agropecuária. Sistema brasileiro de classificação dos solos. Brasília: EMBRAPA, 2006. 306p.

Fagundes, J. L.; Moreira, A. L.; Freitas, A. W. P.; Zonta, A.; Henrichs, R.; Rocha, F. C. Produção de forragem de Tifton 85 adubado com nitrogênio e submetido à lotação contínua. Revista Brasileira de Produção Animal, v.13, p.306-317, 2012. http://dx.doi. org/10.1590/S1519-99402012000200002

Fonseca, A. F.; Melfi, A. J.; Monteiro, F. A.; Montes, C. R.; Almeida, V. V. D.; Herpin, U. Treated sewage effluent as a source of water and nitrogen for Tifton 85 bermudagrass. Agricultural Water Management, v.87, p.328-336, 2007. http://dx.doi.org/10.1016/j. agwat.2006.08.004

Furlan, B. N.; Simili, F. F.; Reis, R. A.; Godoy, R.; Ferereira, D. D. S.; De, A. G. Faião, C. A.; Yoshimura, M. L. Sobressemeadura de cultivares de aveia em pastagem de capim Tifton-85. 2005. http://ainfo.cnptia.embrapa.br/digital/bitstream/CPPSE/15766/1/ PROCIRG2005.00061.PDF

Genuchten, M. Th. van. A closed-from equation for predicting the conductivity of unsaturated soils. Soil Science Society of American Journal, v.44, p.892-898, 1980. http://dx.doi.org/10.2136/ sssaj1980.03615995004400050002x

IAPAR - Instituto Agronômico do Paraná, 2012. http://www.iapar.br/ modules/conteudo/conteudo.php?conteudo=863. 14 Fev. 2012.

Moreira, A. L.; Reis, R. A.; Simili, F. F.; Gomide, C. A. D. M.; Ruggieri, A. C.; Berchielli, T. T. Nitrogen and carbohydrate fractions in exclusive Tifton 85 and in pasture oversown with annual winter forage species. Acta Scientiarum. Animal Sciences, v.34, p.7-14, 2012. 
Moreira, A. L.; Reis, A. R.; Simili; F. F.; Pedreira, M. S.; Contato, E. D.; Ruggieri, A. C. Época de sobressemeadura de gramíneas anuais de inverno e de verão no capim Tifton 85: produção e composição botânica. Ciência e Agrotecnologia, v.30, p.739-745, 2006a. http:// dx.doi.org/10.1590/S1413-70542006000400021

Moreira, A. L.; Reis, R. A.; Simili, F. F.; Pedreira, M. D. S.; Roth, M. D. T. P.; Ruggieri, A. C. Época de sobressemeadura de gramíneas anuais de inverno e de verão no capim-Tifton 85: Valor nutritivo. Ciência e Agrotecnologia, v.30, p. 335-343, 2006b. http://dx.doi. org/10.1590/S1413-70542006000200021

Neres, M. A.; Castagnara, D. D.; Mesquita, E. E.; Jobim, C. C.; Três, T. T., Oliveira; P. S. R.; Oliveira, A. A. M. D. A. Production of tifton 85 hay overseeded with white oats or ryegrass. Revista Brasileira de Zootecnia, v.40, p.1638-1644, 2011. http://dx.doi.org/10.1590/ S1516-35982011000800003

Nogueira, S. F.; Pereira, B. F. F.; Gomes, T. M.; De Paula, A. M.; Dos Santos, J. A.; Montes, C. R. Treated sewage effluent: Agronomical and economical aspects on bermudagrass production. Agricultural Water Management, v.116, p.151-159, 2013. http://dx.doi. org/10.1016/j.agwat.2012.07.005

Olivo, C. J.; Meinerz, G. R.; Agnolin, C. A.; Steinwandter, E.; Ziech, M. F.; Skonieski, F. R. Produção de forragem e carga animal de pastagens de Coastcross sobressemeadas com forrageiras de inverno. Revista Brasileira de Zootecnia, v.39, p.68-73, 2010. http://dx.doi.org/10.1590/S1516-35982010000100009

Queiroz, D. S.; Menezes, M. A.C.; Oliveira, R. A. D.; Viana, M. C. M.; Silva, E. A. D.; Ruas, J. R. M. Nitrogen fertilization strategies for xaraes and tifton 84 grasses irrigated in the dry season. Revista Brasileira de Zootecnia, v.41, p.1832-1839, 2012. http://dx.doi. org/10.1590/S1516-35982012000800005

Rassini, J. B. Período de estacionalidade de produção de pastagens irrigadas. Pesquisa Agropecuária Brasileira, v.39, p.821-825, 2004 http://dx.doi.org/10.1590/S0100-204X2004000800014
Ribeiro, K. G., E Pereira, O. G. Produtividade de matéria seca e composição mineral do capim-Tifton 85 sob diferentes doses de nitrogênio e idades de rebrotação. Ciência e Agrotecnologia, v.35, p.811-816, 2011. http://dx.doi.org/10.1590/S141370542011000400022

Rocha, G. P.; Evangelista, A. R.; Lima, J. A. Nitrogênio na produção de matéria seca, teor e rendimento de proteína bruta de gramíneas tropicais. Pastures Tropicales, v.22, p.4-8, 2000.

Rocha, M. G. D.; Pereira, L. E. T.; Scaravelli, L. F. B.; Olivo, C. J.; Agnolin, C. A.; Ziech, M. F. Produção e qualidade de forragem da mistura de aveia e azevém sob dois métodos de estabelecimento. Revista Brasileira de Zootecnia, v.36, p.7-15, 2007. http://dx.doi. org/10.1590/S1516-35982007000100002

Silva, C. D.; Menezes, L. D.; Ziech, M. F.; Kuss, F.; Ronsani, R.; Biesek, R. R.; Lisbinski, E. Sobressemeadura de cultivares de aveia em pastagem de estrela africana manejada com diferentes resíduos de forragem. Semina: Ciências Agrárias, v.33, 2441-2450, 2012. http://dx.doi.org/10.5433/1679-0359.2012v33n6p2441

Silva, D. J.; Queiroz, A. C. Análise de alimentos: Métodos químicos e biológicos. 3.ed. Viçosa: UFV, 2002. 235p.

Silva, F. de A. S. e; Azevedo, C. A. V. de. Principal components analysis in the software assistat-statistical attendance. In: World Congress on Computers in Agriculture, 7, Reno. Proceedings....Reno: American Society of Agricultural and Biological Engineers, 2009. CD-Rom Soares Filho, C. V.; Rodrigues, L. R. A.; Perri, S. H. V. Produção e valor nutritivo de dez gramíneas forrageiras na região Noroeste do Estado de São Paulo. Acta Scientiarum Agronomy, v.24, p.1377-1384, 2002.

Teixeira, A. M.; Jayme, D. G.; Sene, G. A.; Fernandes, L. O. Barreto, A. C.; Rodrigues Júnior, D. J.; Glória, J. R. Desempenho de vacas Girolando mantidas em pastejo de Tifton 85 irrigado ou sequeiro. Arquivo Brasileiro de Medicina Veterinária e Zootecnia, v.65, p.1447-1453, 2013. http://dx.doi.org/10.1590/S0102-09352013000500025 